\title{
Parents' Perceptions on Anxiety Symptoms in Children With Autism Spectrum Disorder
}

\author{
Christine K. Syriopoulou-Delli ${ }^{1}$, Stavroula A. Polychronopoulou ${ }^{2}$, \\ Gerasimos A. Kolaitis ${ }^{3} \&$ Alexandros-Stamatios G. Antoniou ${ }^{4}$ \\ ${ }^{1}$ Department of Educational and Social Policy, University of Macedonia, Greece \\ ${ }^{2}$ Department of Primary Education, National and Kapodistrian University of Athens, Greece \\ ${ }^{3}$ Department of Child Psychiatry, School of Medicine, National and Kapodistrian University of Athens, "Aghia \\ Sophia" Children's Hospital, Greece \\ ${ }^{4}$ Department of Primary Education, National and Kapodistrian University of Athens, Greece \\ Correspondence: Christine K. Syriopoulou Delli, Postdoc, Assistant Professor, Autism Spectrum Disorders, \\ Department of Educational and Social Policy, University of Macedonia, Thessaloniki, 156 Egnatia str., 54336 \\ Thessaloniki, Greece. Tel: 30-693-870-4339. E-mail: csyriop@gmail.com
}

Received: July 31, 2019 Accepted: August 19, 2019 Online Published: September 6, 2019

doi:10.5539/jedp.v9n2p104 URL: http://doi.org/10.5539/jedp.v9n2p104

\begin{abstract}
People with Autism Spectrum Disorder (ASD) exhibit comorbidity with anxiety. In anxiety management programs, parents take on the role of the supporter, trainer, and friend. This study investigated the views of parents on anxiety symptoms in schoolchildren with ASD using the Screen for Child Anxiety Related Disorders - Parent Version (SCARED-PV) questionnaire. The perception of parents of children of typical development (TD) was also studied. According to parental assessment, $95.6 \%$ of the children with ASD and $20 \%$ of those of TD showed anxiety levels within the clinical spectrum of the disorder. Parents have an integral role in managing anxiety in their children with ASD.
\end{abstract}

Keywords: autism spectrum disorder, parents, anxiety, perceptions, role, recommendations

\section{Introduction}

Autism Spectrum Disorder (ASD), as defined by Diagnostic and Statistical Manual of Mental Disorders (DSM-5 (American Psychiatric Association, 2013), is characterized by qualitative weaknesses in social interaction and communication and limited, repetitive and stereotypical patterns of behaviour, interests and activities (APA, 2013). The documented rate of anxiety in children with ASD varies from $11 \%$ to $84 \%$, depending on the sample, the methodology and the source of information (White et al., 2009), and up to $40 \%$ have been diagnosed with at least one DSM anxiety disorder at some point in their life (VanSteensel et al., 2011). Parental studies and self-reports give higher rates of anxiety symptoms for young people with ASD than those of typical development (TD) (Bradley et al., 2004; Simonoff et al., 2008; MacNeil et al., 2009; Gillot et al., 2001). Anxiety in young people with ASD can aggravate social deficiencies and daily living skills and have negative effects on their relationships with peers, teachers and families (Drahota et al., 2011; Kim et al., 2000). In children of TD, untreated childhood anxiety can lead to long-term psychopathology (Pine et al., 1998). Children with ASD may have similar long-term consequences of anxiety, which can intensify their social cognitive and linguistic weaknesses (Merikangas et al., 2010; Bradley et al., 2004; White, Oswald, Ollendick, \& Scahill, 2009). Stress may manifest itself in different ways in children with ASD, which may impede its recognition (Dekker \& Koot, 2003; Evans et al., 2005; Costell et al., 2005). This increases the risk of failure to provide adequate support to these children in their social interaction and adaptation to the school environment. Certain characteristics of ASD, such as communication difficulties, may interfere with the stress assessment process. Many children with ASD have a great deal of difficulty understanding and interpreting their feelings (Attwood, 2005; Yen, 2002, 2011; Polychronopoulou, 2012). Anxiety in children with ASD makes them more vulnerable to stressful situations, and they need greater support and specific psych-pedagogical intervention (Ventola et al., 2017).

According to the educational and social policy in Greece (Greek Official Government Gazette, 2008), children with ASD should be educated in a less restrictive environment, preferably in the regular classes of the mainstream 
schools. Many factors make the practical application of "one school for all" difficult (Papadatos, 2010; Ghaziuddin, 2005; Gillot et al., 2001; Klin et al., 2000; Muris et al., 1998). Every social contact can create anxiety in the children with ASD as they need to make an effort to start, maintain and complete an activity or discussion (Russell and Sofronoff, 2005; Bellini, 2004). In this context, the school is a social minefield, provoking anxiety and aggravating each child's characteristic symptoms (O'Nions, Happé, Evers, Boonen, \& Noens, 2017). It is therefore of great importance to find ways of assessing anxiety in school children with ASD in order to design and to provide timely appropriate psycho-pedagogical intervention that will facilitate their school and social inclusion. Anxiety symptoms influence the educational performance of children with ASD and their inclusion. Parents have an integral role in managing the anxiety of their children with ASD, taking on the role of supporter, trainer and friend (Wood et al., 2009; Højgaard, Skarphedinsson, Nissen, Hybel, Ivarsson, \& Thomsen, 2017). Despite the importance of this topic, it has still not been adequately researched.

Bitsika and Sharpley (2017) recently investigated the perceptions of parents on anxiety in their children with ASD. The present study was conducted with a view to replicating and expanding on their research and, contributing further insight into the anxiety of children with ASD and their parents' views of the problem.

The purpose of the study was threefold:

(i) to clarify the views of parents on anxiety in their children with ASD.

(ii) to detect possible differences in the level of anxiety in children with ASD and those of TD.

(iii) to propose suggestions for parents on the management support of their children in coping with anxiety.

Specifically, the study attempted answer the following research questions:

a) What is the perception of parents on anxiety in their children with ASD?

b) Are there differences in the perception of their children's anxiety between parents of children with ASD and those of TD?

c) What can parents of children with ASD do to better manage their children's anxiety symptoms and how can they best support their children?

\section{Methods}

Anxiety in Greek children with and without ASD attending school was assessed by eliciting the views of their parents, and related factors were explored.

\subsection{Data Collection Process}

Questionnaires were distributed and collected by the researcher between September 2016 and May 2017. Parents with a child with ASD were located through the school units (mainstream or special) attended by with ASD. Parents of children of TD as a control population were approached through general education schools throughout Greece. The research questionnaires and an accompanying letter (see Appendix) detailing the purpose and objectives of the study were distributed in paper or electronic form. Participation in the study was voluntary.

Parents who were invited to participate were asked to fill in the questionnaire completely. The researcher's mobile phone was made available, prompting them to make contact for instructions and clarifications. Particular emphasis was placed on the importance of confidentiality and anonymity of information, namely that the data on the children and parents will remain anonymous and that the information will be used solely for the purposes of this study. The importance to the research objectives of the provision of the true data was emphasized.

The completed questionnaires were to be returned within 30 days of the date of their original delivery. Incomplete questionnaires or questionnaires which were received after the given deadline were excluded from analysis.

\subsection{Data Collection Tools}

The instrument used to elicit data on the study children by their parents was the Screen for Child Anxiety Related Disorders - Parent Version (SCARED- PV) (see Appendix). This tool calculates the anxiety of the child under consideration based on the parent's views. The psychometric properties of the SCARED-PV have been well established with parents of children of TD by Birmaher's original validation studies (Birmaher, 1997; 1999), and subsequent research (Silverman and Olendick, 2005; Hale et al., 2011), including with parents of children with ASD (Stern et al., 2015). High internal consistency ( $>0.9$ ) was found in its use with both ASD and TD groups.

The SCARED-PV contains 41 closed-ended questions that follow a 3-step Likert scale: $0=$ "It is not true or is rarely true", 1 = "It is true sometimes or only a few times", and 2 = "It is always true or true very often". These 41 questions are grouped into five subscales as follows: 


\section{1). Excessive Concern (Panic Disorder or Significant Somatic Symptoms - PN)}

This consists of the 13 questions: 1, 6, 9, 12, 15, 18, 19, 22, 24, 27, 30, 34 and 38. The sum of the scores gives a range of from 0 to 26; a score of higher than 6 on this subscale indicates the presence of PN.

\section{2). Generalized Anxiety (Generalized Anxiety Disorder - GD)}

This consists of the 9 questions: 5, 7, 14,21, 23, 28, 33, 35 and 37. The sum of the scores gives a range between 0 and 18. A total score of more than 8 points on this subscale suggests the presence of GA.

\section{3). Separation Anxiety (Separation Anxiety - SP)}

The 8 questions constituting this sub-scale are: $4,8,13,16,20,25,29$ and 31, giving a possible score of 0 to 16 . Score of over 5 indicates SOC-SP.

4). Social Phobia (Social Anxiety Disorder- SC)

The 7 questions making up this subscale are: $3,10,26,32,39,40$ and 41 . The sum of the responses gives a score of 0 to 14. A score of higher than 7 is indicative of SC.

\section{5). School Anxiety (Significant School Avoidance - SH)}

This subscale is calculated from the sum of 4 questions: 19, 46, 54 and 56 of the questionnaire, with a possible score of from 0 to 8 . A score of over 2 points indicates $\mathrm{SH}$.

The total score for anxiety disorder is derived from the sum of the 5 subscales, with a range of from 0 to 82 units. On the total anxiety score, as on all of its individual subscales, higher scores indicate higher level of anxiety. Total scores on the SCAED-PV of 0 to 24 are considered to represent normal levels of anxiety and scores of from 25 to 30 marginal, while scores of above 30 units indicate the clinical spectrum of anxiety disorder.

The SCARED-PV was accompanied by a short questionnaire covering demographic characteristics related to the parents who participated in the study and data about the index children (see Appendix).

\subsection{Statistical Analysis}

A consistency check was conducted through Cronbach's alpha factor, which determines the reliability of data collection tools and their individual parts. Rates greater than 0.6 are considered satisfactory and ensure the consistency and internal validity, acting as elements of a single group. Prices from 0.6 ensure coherence of particular parts and their role as parts of a whole group (Arab et al., 2016).

Quantitative variables were expressed as Mean \pm standard deviation (SD), range [minimum and maximum values (Min - Max)], and third and fourth order (Skewness and kurtosis) of their distributions. Qualitative variables were expressed as absolute (n) and percentages (\%).

Linear correlation between quantitative variables was explored using the Pearson $r$. The correlation coefficient $r$ takes values between -1 and 1: the greater the absolute value, the greater the correlation between the variables. The statistical significance of the correlations is checked at significance levels $a=1 \%$ and $a=5 \%$.

For comparison of quantitative variables, Independent Samples t-test and the Kruskal Wallis test. Levene's test was used to check the hypothesis of dispersion equilibrium at factor levels, and the Kolmogorov- Smirnov test and the Runs test respectively to test the basic conditions for the regularity and independence of method errors.

The IBM SPSS Statistics 20 statistical analysis software package was used for data processing and statistical analysis.

\section{Results}

\subsection{The Sample Population}

\section{The Parents}

Of the 800 parents with children with ASD who were invited to participate in the study 634 parents returned completed questionnaires within the time stipulated. Most of the responses were complete but 4 were either were either incomplete or unsuitable for analysis. The study recruited 630 parents with children with ASD, of whom 307 (48.7\%) were the fathers and $323(51.3 \%)$ the mothers of the children for which they provided information. The parents of children with ASD ranged in age from 21 to 54 years, mean $33 \pm 4.85$ years.

Similarly, of 800 parents of children of TD approached, 207 returned completed questionnaires of children of TD of which 178 were suitable for analysis. The study included 178 parents of children of TD, for comparison. A higher proportion of mothers of TD provided information, $85.4 \%(n=152)$, and only 26 fathers $(14.6 \%)$. The parents of the children of TD were aged $39.85 \pm 5.9$ years, with a range of $23-45$ years. The characteristics of all the 
study parents are shown in Table 1.

Table 1. Demographic characteristics of the parents who participated in the study $(n=808)$.

\begin{tabular}{|c|c|c|c|c|c|}
\hline & \multicolumn{3}{|c|}{$\begin{array}{l}\text { Parents of children with Autism } \\
\text { Spectrum Disorders } \\
(n=630)\end{array}$} & \multicolumn{2}{|c|}{$\begin{array}{l}\text { Parents of children of typical } \\
\text { development } \\
(n=178)\end{array}$} \\
\hline & $\mathbf{N}$ & $\%$ & & $\mathbf{N}$ & $\%$ \\
\hline \multicolumn{6}{|l|}{ Gender } \\
\hline Men & 307 & 48.7 & & 26 & 14.6 \\
\hline Women & 323 & 51.3 & & 152 & 85.4 \\
\hline \multicolumn{6}{|l|}{ Family status } \\
\hline Married & 617 & 97.9 & & 154 & 86.6 \\
\hline Divorced & 10 & 1.6 & & 16 & 9.0 \\
\hline Single & 3 & 0.5 & & 4 & 2.2 \\
\hline New Companion/ spouse & 0 & 0.0 & & 4 & 2.2 \\
\hline \multicolumn{6}{|l|}{ Educational Level } \\
\hline Master's Degree & 19 & 3.0 & & 4 & 2.2 \\
\hline Bachelor's Degree & 155 & 24.6 & & 68 & 38.2 \\
\hline $\begin{array}{l}\text { Certificate of Higher Technological } \\
\text { Institute }\end{array}$ & 65 & 10.3 & & 34 & 19.1 \\
\hline High School Certificate & 249 & 39.5 & & 64 & 36.0 \\
\hline Primary Education Certificate & 128 & 20.5 & & 6 & 3.4 \\
\hline Did not finish primary school & 15 & 2.4 & & 2 & 1.1 \\
\hline \multicolumn{6}{|l|}{ Financial Situation } \\
\hline Comfortable / wealthy & 209 & 49.0 & & 18 & 10.1 \\
\hline Average & 232 & 36.8 & & 140 & 78.7 \\
\hline Poor & 8 & 1.3 & & 14 & 7.9 \\
\hline Hard & 81 & 12.9 & & 6 & 3.4 \\
\hline
\end{tabular}

\section{The Children}

All the children in the study were attending school, with the exception of $13(2.1 \%)$ of the individuals with ASD who attended Centers of Creative Occupation for individuals with special needs. The characteristics of all the study children are shown in Table 2. 
Table 2. Characteristics of the children with Autism Spectrum Disorder(ASD) $(n=630)$ and of typical development (TD) $(\mathrm{n}=178)$

\begin{tabular}{lllll}
\hline & ASD & TD & \% \\
& N & & N & \\
\hline Sex & & & & \\
Boy & 463 & 73.5 & 103 & 57.9 \\
Girl & 167 & 26.5 & 75 & 42.1 \\
\hline School grade & & & & \\
Kindergarten and Primary School & 591 & 93.8 & 160 & 89.9 \\
Gymnasium and Lyceum (Secondary) & 26 & 4.1 & 18 & 10.1 \\
Centers of Creative Occupation for Individuals with Special Needs & 13 & 2.1 & - & - \\
\hline Speech Ability & & & & \\
Without speech & 86 & 13.7 & - & - \\
One word speech & 277 & 44.0 & - & - \\
Developed speech & 267 & 42.3 & 178 & 100.0 \\
\hline
\end{tabular}

Of the children with ASD, 463 (73.5\%) were boys and the 167 (26.5\%) girls. Their age ranged from 4 to 25 years, mean age $10 \pm 3$ years, and most $(591,93.8 \%)$ were in primary school. Their IQ and speech had been assessed by the personnel of Centers of Diagnosis and Differential Diagnosis and Support, who had made the diagnosis of ASD. The mean IQ of the children with ASD was $91.33 \pm 21.2$, ranging from 50 to $150 ; 13.7 \%(\mathrm{n}=86)$ had no speech, $44 \%$ $(\mathrm{n}=277)$ had monosyllabic speech while the remaining $267(42.3 \%)$ had developed verbal ability.

Of the 178 study children of TD, 103 (57.9\%) were boys and 75 (42.1\%) were girls. They ranged in age between 5 and 13 years, mean age $9.8 \pm 3.25$ years. Their IQ was not measured, but none had learning or speech difficulties.

\section{Reliability of the data collection instrument}

Reliability testing was carried out for the Scared-PV and its subscales, for the whole study sample and the ASD and TD groups. Table 3 shows the Cronbach's alpha internal coherence coefficient, which was satisfactory for all the subgroups (greater than 0.600).

Table 3. Reliability of the Screen for Child Anxiety Related Disorders - Parent Version (SCARED-PV) and its sub-scales

\begin{tabular}{clll}
\hline Anxiety Disorders Subscales & (ASD) & $\begin{array}{l}\text { Cronbach's alpha } \\
\text { (Typical Development) }\end{array}$ & (Total) \\
\hline Excessive Concern (PN) & 0.831 & 0.903 & 0.955 \\
Generalised Anxiety (GD) & 0.724 & 0.785 & 0.912 \\
Separation Anxiety (SP) & 0.712 & 0.805 & 0.902 \\
Social Phobia (SC) & 0.672 & 0.839 & 0.887 \\
School Anxiety (SH) & 0.588 & 0.820 & 0.859 \\
\hline Total Anxiety Disorder & 0.933 & 0.945 & 0.982 \\
\hline
\end{tabular}

\section{Responses to the SCARED-PV questionnaire}

The parent's responses to the SCARED-PV questionnaire are presented in Table 4, for the children with ASD, and Table 5 for the children of TD. 
Table 4. Responses of parents of children with ASD to the Screen for Child Anxiety Related Disorders- Parent Version (SCARED-PV) $(n=630)$

\begin{tabular}{|c|c|c|c|}
\hline & $\begin{array}{l}\text { Not true or } \\
\text { rarely true }\end{array}$ & $\begin{array}{l}\text { True sometimes or } \\
\text { true only a few times }\end{array}$ & $\begin{array}{l}\text { Always true or } \\
\text { true vey often }\end{array}$ \\
\hline & $\mathbf{N}$ & $\mathbf{N}$ & $\mathbf{N}$ \\
\hline & $(\%)$ & $(\%)$ & $(\%)$ \\
\hline 1. When my child feels scared, he/she has difficulty breathing. & $114(18.1)$ & $472(74.9)$ & $44(7.0)$ \\
\hline 2. He/She has headaches when he/she is in school. & $115(18.3)$ & $468(74.3)$ & $47(7.5)$ \\
\hline 3. He /She does not like to be with people who does not know well. & $118(18.7)$ & $423(67.1)$ & $89(14.1)$ \\
\hline 4. Feels afraid to sleep away from home. & $130(20.6)$ & $310(49.2)$ & $190(30.2)$ \\
\hline 5. Worries about being liked by others. & $127(20.2)$ & $215(34.1)$ & $288(45.7)$ \\
\hline 6. When scared, feels like he/she is losing his/her senses. & $114(18.1)$ & $162(25.7)$ & $354(56.2)$ \\
\hline 7. Is nervous. & $78(12.4)$ & $157(24.9)$ & $395(62.7)$ \\
\hline 8. Follows me everywhere I go & $68(10.8)$ & $165(26.2)$ & $397(63.0)$ \\
\hline 9. Others tell me my child looks nervous. & $50(7.9)$ & $172(27.3)$ & $408(64.8)$ \\
\hline $\begin{array}{l}\text { 10. My child feels nervous around people he/she does not know } \\
\text { well. }\end{array}$ & $38(6.0)$ & $163(25.9)$ & $429(68.1)$ \\
\hline 11. Has stomach aches at school. & $44(7.0)$ & $164(26.0)$ & $422(67.0)$ \\
\hline 12. When scared feels like he/she is going crazy. & $36(5.7)$ & $123(19.5)$ & $471(74.8)$ \\
\hline 13. Worries about sleeping alone. & $27(4,3)$ & $116(18.4)$ & $487(77.3)$ \\
\hline $\begin{array}{l}\text { 14. My child is concerned whether he/she is as good as the other } \\
\text { children. }\end{array}$ & $23(3.7)$ & $112(17.8)$ & $495(78.6)$ \\
\hline $\begin{array}{l}\text { 15. When scared he/she feels like he/she is experiencing unreal } \\
\text { situations. }\end{array}$ & $27(4.3)$ & $133(21.1)$ & $470(74.6)$ \\
\hline $\begin{array}{l}\text { 16. Has nightmares that something bad is going to happen to his } \\
\text { /her parents }\end{array}$ & $31(4.9)$ & $134(21.3)$ & $465(73.8)$ \\
\hline 17. Worries when thinks that he/she is going to school. & $27(4.3)$ & $181(28.7)$ & $422(67.0)$ \\
\hline 18. When scared his/her heart beats very fast. (fast-paced) & $19(3.0)$ & $277(44.0)$ & $334(53.0)$ \\
\hline 19. My child has begun to become fearful (dangerous). & $27(4.3)$ & $426(67.6)$ & $177(28.1)$ \\
\hline $\begin{array}{l}\text { 20. Often has nightmares about whether something bad will } \\
\text { happen to him/her. }\end{array}$ & $36(5.7)$ & $529(84.0)$ & $65(10.3)$ \\
\hline 21. Is worried about whether things will go well. & $24(3.8)$ & $529(84.0)$ & $77(12.2)$ \\
\hline 22. When scared, sweats too much. & $34(5.4)$ & $455(72.2)$ & $141(22.4)$ \\
\hline 23. Worried about anything. & $30(4.8)$ & $408(64.8)$ & $192(30.5)$ \\
\hline 24. Scared for real for no reason. & $33(5.2)$ & $368(58.4)$ & $229(36.3)$ \\
\hline 25. Scared to be alone in the house. & $26(4.1)$ & $99(15.7)$ & $505(80.2)$ \\
\hline 26. Finds difficult to speak to someone he/she does not know well. & $19(3.0)$ & $101(16.0)$ & $510(81.0)$ \\
\hline 27. When scared feels like drowing. & $38(6.0)$ & $82(13.0)$ & $510(81.0)$ \\
\hline 28. Others tell me my child worries too much. & $31(4.9)$ & $85(13.5)$ & $514(81.6)$ \\
\hline 29. My child does not like being away from his/her family. & $11(1.7)$ & $133(21.1)$ & $486(77.1)$ \\
\hline 30. Scared whether he/she is going to have an anxiety crisis. & $35(5.6)$ & $146(23.2)$ & $449(71.3)$ \\
\hline $\begin{array}{l}\text { 31. He/She is worried that something bad will happen to his /her } \\
\text { parents. }\end{array}$ & $27(4.3)$ & $157(24.9)$ & $446(70.8)$ \\
\hline 32. Feels shy with people who he/she does not know well. & $17(2.7)$ & $159(25.2)$ & $454(72.1)$ \\
\hline
\end{tabular}


33. Is worried about what is going to happen in the future.

34. When he/she gets scared, he/she feels like he/she is going to vomit.

35. He/She is worried about how well he/she can do different things.

36. Afraid to go to school.

37 . He/ She is worried about things that have already happened.

38. When scared feels like dizzy.

39. Feels nervous when he/she is with other children or adults and he/she has to do something while others look at him /her (for example to read loud or speak, etc).

40. Feels nervous when he/she goes to parties, dances or other places where there are people who he/she does not know them well.

41. Is very shy.

$\begin{array}{lll}25(4.0) & 148(23.5) & 457(72.5) \\ 31(4.9) & 158(25.1) & 441(70.0) \\ 19(3.0) & 170(27.0) & 441(70.0) \\ 30(4.8) & 191(30.3) & 409(64.9) \\ 23(3.7) & 189(30.0) & 418(66.3) \\ 29(4.6) & 195(31.0) & 406(64.4) \\ 16(2.5) & 232(36.8) & 382(60.6) \\ 14(2.2) & 361(57.3) & 255(40.5) \\ 16(2.5) & 439(69.7) & 175(27.8)\end{array}$

Table 5. Response of Parents of Children of Typical Development to the Screen for Child Anxiety Related Disorders - Parent Version (SCARED-PV) $(n=178)$ 
19. My child has begun to become fearful (dangerous).

\begin{tabular}{|c|c|c|}
\hline $172(96.6)$ & $6(3.4)$ & $0(0.0)$ \\
\hline $158(88.8)$ & $20(11.2)$ & $0(0.0)$ \\
\hline $104(58.4)$ & $68(38.2)$ & $6(3.4)$ \\
\hline $130(73.0)$ & $38(21.3)$ & $10(5.6)$ \\
\hline $140(78.7)$ & $28(15.7)$ & $10(5.6)$ \\
\hline $162(91.0)$ & $4(2.2)$ & $12(6.7)$ \\
\hline $94(52.8)$ & $52(29.2)$ & $32(18.0)$ \\
\hline $100(56.2)$ & $66(37.1)$ & $12(6.7)$ \\
\hline $158(88.8)$ & $18(10.1)$ & $2(1.1)$ \\
\hline $154(86.5)$ & $20(11.2)$ & $4(2.2)$ \\
\hline $92(51.7)$ & $60(33.7)$ & $26(14.6)$ \\
\hline $160(89.9)$ & $18(10.1)$ & $0(0.0)$ \\
\hline $126(70.8)$ & $44(24.7)$ & $8(4.5)$ \\
\hline $82(46.1)$ & $76(42.7)$ & $20(11.2)$ \\
\hline $128(71.9)$ & $46(25.8)$ & $4(2.2)$ \\
\hline $160(89.9)$ & $18(10.1)$ & $0(0.0)$ \\
\hline $112(62.9)$ & $60(33.7)$ & $6(3.4)$ \\
\hline $158(88.8)$ & $20(11.2)$ & $0(0.0)$ \\
\hline $142(79.8)$ & $36(20.2)$ & $0(0.0)$ \\
\hline $164(92.1)$ & $14(7.9)$ & $0(0.0)$ \\
\hline $124(69.7)$ & $48(27.0)$ & $6(3.4)$ \\
\hline $144(80.9)$ & $20(11.2)$ & $14(7.9)$ \\
\hline $122(68.5)$ & $40(22.5)$ & $16(9.0)$ \\
\hline
\end{tabular}

20. He/She often has nightmares about whether something bad will happen to him/her.

21. He/She is worried about whether things will go well.

22. When he/she is scared, he/she sweats too much.

23. Worries about anything.

24. He/She gets scared for real for no reason.

25. Afraid to be home alone.

26. He/She finds it hard to talk to someone who does not know well.

27. When he/sh is scared, he/she feels like choking.

28. The others tell me that my child worries too much.

29. My child does not like being away from his/her family.

30. He/She is afraid of anxiety crisis (panic).

31. He/She is worried that something ugly will happen to his/her parents.

32. He/She feels shy with people who he/she does not know well.

33. He/She is worried about what is going to happen in the future.

34. When he/she gets scared, he/she feels like he/she is going to vomit.

35. He/She is worried about how well he/she can do different things.

36. Is afraid to go to school.

37. $\mathrm{He} / \mathrm{She}$ is worried about things that have already happened.

38. When scared feels like dizzy.

39. Feels nervous when he/she is with other children or adults and he/she has to do something while others look at him /her (for example to read loud or speak, etc).

40. Feels nervous when he/she goes to parties, dances or other places where there are people who he/she does not know them well.

41. Is very shy.

\section{Scores on the SCARED- PV questionnaire}

Table 6 shows the mean scores for the children with ASD on the SCARED-PV and its five subscales. 
Table 6. Anxiety Disorder as measured by the Screen for Child Anxiety Related Disorders - Parent Version (SCARED-PV) and its subscales for children with Autism Spectrum Disorder $(n=630)$

\begin{tabular}{|c|c|c|c|c|c|}
\hline Anxiety Disorder \& Subscales & Mean & SD & Range & Skewness & Kurtosis \\
\hline $\begin{array}{l}\text { Anxiety Disorder SCARED-PV (total score) } \\
\text { (Scale: } 0-82 \text { ) }\end{array}$ & 60.95 & 12.04 & $1-79$ & -2.598 & 7.903 \\
\hline $\begin{array}{l}\text { Excessive Concern (PN) } \\
(\text { Scale: } \quad-26)\end{array}$ & 19.11 & 4.31 & $0-25$ & -2.654 & 7.992 \\
\hline $\begin{array}{l}\text { Generalised Anxiety (GD) } \\
\text { (Scale: } \quad-18)\end{array}$ & 13.60 & 2.88 & $0-18$ & -2.201 & 6.704 \\
\hline $\begin{array}{l}\text { Separation Anxiety (SP) } \\
\text { (Scale: } \quad-16)\end{array}$ & 12.26 & 2.58 & $0-16$ & -2.114 & 5.604 \\
\hline $\begin{array}{l}\text { Social Phobia (SC) } \\
\text { (Scale: } \quad-14)\end{array}$ & 10.26 & 2.17 & $0-14$ & -1.420 & 4.038 \\
\hline $\begin{array}{l}\text { School Anxiety }(\mathrm{SH}) \\
(\text { Scale: } 0-8)\end{array}$ & 5.72 & 1.52 & $0-8$ & -1.825 & 4.126 \\
\hline
\end{tabular}

It is of note that on the total anxiety scale, from a possible score of 82 , the mean score of the children with ASD was $61 \pm 12$. Their scores on the subscales were correspondingly high.

The mean scores of the children of TD on the SCARED-PV and its five subscales are shown Table 7.

Table 7. Anxiety Disorder as measured by the Screen for Child Anxiety Related Disorders - Parent Version (SCARED-PV) and its subscales for children of typical development $(n=178)$

\begin{tabular}{|c|c|c|c|c|c|}
\hline Anxiety Disorder \& Subscales & Mean & SD & Range & Skewness & Kurtosis \\
\hline $\begin{array}{l}\text { Anxiety Disorder SCARED-PV (total) } \\
\text { (Scale: } 0-82 \text { ) }\end{array}$ & 12.71 & 12.01 & $0-55$ & 1.649 & 2.639 \\
\hline $\begin{array}{l}\text { Excessive Concern (PN) } \\
(\text { Scale: } \quad-26)\end{array}$ & 2.26 & 3.61 & $0-16$ & 2.319 & 4.984 \\
\hline $\begin{array}{l}\text { Generalised Anxiety (GD) } \\
\text { (Scale: } \quad-18)\end{array}$ & 3.29 & 2.94 & $0-12$ & 1.089 & 0.725 \\
\hline $\begin{array}{l}\text { Separation Anxiety (SP) } \\
(\text { Scale: } \quad-16)\end{array}$ & 3.37 & 3.35 & $0-14$ & 1.054 & 0.622 \\
\hline $\begin{array}{l}\text { Social Phobia (SC) } \\
\text { (Scale: } \quad-14)\end{array}$ & 3.02 & 3.02 & $0-12$ & 1.124 & 0.654 \\
\hline $\begin{array}{l}\text { School Anxiety }(\mathrm{SH}) \\
(\text { Scale: } 0-8)\end{array}$ & 0.76 & 1.29 & $0-4$ & 1.453 & 0.693 \\
\hline
\end{tabular}

$\mathrm{SD}=$ standard deviation.

On the total anxiety scale, the mean score of the children of TD was $13 \pm 12$, of a possible 82 , with correspondingly low mean scores on the five subscales.

As described in the methodology section based on the responses to the SCARED-PV questions, the children can be classified as being in one of three levels of anxiety for the total scale, as perceived by their parents, namely "normal range", "marginal" and "clinical", while for all its sub-scales the classification is into "normal" and "clinical". Based on this classification, for the total score, $95.6 \%$ of the children with ASD were in the clinical range of anxiety, $3.8 \%$ in the normal range and $0.6 \%$ in the marginal range. Table 8 shows the distribution of the children 
with ASD according to the scores on SCARED-PV.

Table 8. Distribution of the scores as measured by the Screen for Child Anxiety Related Disorders - Parent

\begin{tabular}{lll}
\hline & \multicolumn{2}{l}{ Spectrum } \\
\cline { 2 - 3 } SCARED-PV Subscales & Normal & Clinical \\
\cline { 2 - 3 } & $\mathbf{N}(\mathbf{\%})$ & $\mathbf{N}(\mathbf{\%})$ \\
\hline Excessive Concern (PN) & $27(4.3)$ & $603(95.7)$ \\
Generalised Anxiety (GD) & $27(4.3)$ & $603(95.7)$ \\
Separation Anxiety (SP) & $21(3.3)$ & $609(96.7)$ \\
Social Phobia (SC) & $49(7.8)$ & $581(92.2)$ \\
School Anxiety (SH) & $29(4.6)$ & $601(95.4)$ \\
Total SCARED-PV Score & $24(3.9)$ & $602(95.6)$ \\
\hline
\end{tabular}

Based on the same criteria, $86.5 \%$ of the study children of TD were classified in the normal range according to the total anxiety score on the SCARED-PV, 2.2\% marginal, and $11.2 \%$ in the clinical range. Table 9 shows the distribution of the children of TD into anxiety categories according to the scores on SCARED-PV and its subscales.

Table 9. Distribution of the scores of Anxiety Disorders measured by the Screen for Child Anxiety Related Disorders - Parent Version (SCARED-PV) for children of typical development

\begin{tabular}{lll}
\hline & \multicolumn{2}{l}{ Spectrum } \\
\cline { 2 - 3 } Subscales SCARED-PV & Normal & Clinical \\
\cline { 2 - 3 } & $\mathbf{N}(\mathbf{\%})$ & $\mathbf{N}(\mathbf{\%})$ \\
\hline Excessive Cooncern (PN) & $162(91.0)$ & $16(9.0)$ \\
Generalised Anxiety (GD) & $166(93.3)$ & $12(6.7)$ \\
Separation Anxiety (SP) & $120(67.4)$ & $58(32.6)$ \\
Social Phobia (SC) & $162(91.0)$ & $16(9.0)$ \\
School Anxiety (SH) & $152(85.4)$ & $26(14.6)$ \\
Total SCARED-PV score & $154(86.5)$ & $20(11.2)$ \\
\hline
\end{tabular}

Comparison of the anxiety score on SCARED-PV and its subscales between the children with ASD and those of typical development is shown in Table 10. 
Table 10. Comparison of the scores of Anxiety Disorder as measured by the Screen for Child Anxiety Related Disorders - Parents Version SCARED-PV) for children with Autism Spectrum Disorder (ASD) $(n=630)$ and children of typical development (TD) $(\mathrm{n}=178)$

\begin{tabular}{|c|c|c|c|c|c|c|}
\hline Scales \& Sub-scales & Children & Mean & SD & df & $\mathbf{T}$ & p-value \\
\hline \multirow{2}{*}{ Total Anxiety Disorder SCARED-PV } & ASD & 60.95 & 12.035 & \multirow{2}{*}{806} & \multirow{2}{*}{-47.242} & \multirow{2}{*}{$0.000 *$} \\
\hline & T.A. & 12.71 & 12.013 & & & \\
\hline \multirow{2}{*}{ Excessive Concern (PN) } & ASD & 19.11 & 4.308 & \multirow{2}{*}{806} & \multirow{2}{*}{-47.658} & \multirow{2}{*}{$0.000 *$} \\
\hline & T.A. & 2.26 & 3.610 & & & \\
\hline \multirow{2}{*}{ Generalized Anxiety (GD) } & ASD & 13.60 & 2.879 & \multirow{2}{*}{280.477} & \multirow{2}{*}{-41.541} & \multirow{2}{*}{$0.000^{*}$} \\
\hline & T.A. & 3.29 & 2.935 & & & \\
\hline \multirow{2}{*}{ Separation Anxiety (SP) } & $\mathrm{ASD}$ & 12.26 & 2.584 & \multirow{2}{*}{239.632} & \multirow{2}{*}{-32.769} & \multirow{2}{*}{$0.000^{*}$} \\
\hline & T.A. & 3.37 & 3.349 & & & \\
\hline \multirow{2}{*}{ Social Phobia (SC) } & ASD & 10.26 & 2.171 & \multirow{2}{*}{231,013} & \multirow{2}{*}{-29.869} & \multirow{2}{*}{$0.000^{*}$} \\
\hline & T.A. & 3.02 & 3.021 & & & \\
\hline \multirow{2}{*}{ School Anxiety (SH) } & ASD & 5.72 & 1.515 & \multirow{2}{*}{806} & \multirow{2}{*}{-39.800} & \multirow{2}{*}{$0.000^{*}$} \\
\hline & T.A. & 0.76 & 1.285 & & & \\
\hline
\end{tabular}

$\mathrm{SD}=$ standard deviation $*=\mathrm{p}<.05$.

The difference between the scores of the two groups of children was highly statistically significant for the total score and all the five subscales.

As shown in Table 11, the scores of the children with ASD on all the various subscales of SCARED-PV showed strong correlation with each other.

Table 11. Correlation between scores on subscales of Screen for Child Anxiety Related Disorders - Parent Version (SCARED-PV) for children with ASD $(n=690)$ (Pearson $r$ correlation coefficients)

\begin{tabular}{|c|c|c|c|c|c|c|}
\hline Sub-scales SCARED-PV & & PN & GD & SP & SC & SH \\
\hline \multirow{2}{*}{ PN } & Pearson's $r$ & \multirow{2}{*}{1} & $0.852 * *$ & $0.842 * *$ & $0.673 * *$ & $0.770 * *$ \\
\hline & p-value & & 0.000 & 0.000 & 0.000 & 0.000 \\
\hline \multirow{2}{*}{ GD } & Pearson's $r$ & & \multirow{2}{*}{1} & $0.803^{* *}$ & $0.564 * *$ & $0.649 * *$ \\
\hline & p-value & & & 0.000 & 0.000 & 0.000 \\
\hline \multirow{2}{*}{ SP } & Pearson's $r$ & & & \multirow{2}{*}{1} & $0.673 * *$ & $0.702 * *$ \\
\hline & $p$-value & & & & 0.000 & 0.000 \\
\hline \multirow{2}{*}{ SC } & Pearson's $r$ & & & & \multirow{2}{*}{1} & $0.622 * *$ \\
\hline & $p$-value & & & & & 0.000 \\
\hline \multirow{2}{*}{ SH } & Pearson's $r$ & & & & & \multirow{2}{*}{1} \\
\hline & p-value & & & & & \\
\hline
\end{tabular}

\section{Factors associated with SCARED-PV scores of children with ASD}

An attempt was made to explore the relationship of a variety of factors with the level of anxiety in children with ASD, as assessed by their parents.

As reported above, the parent who completed the SCARED-PV questionnaire on anxiety in ASD was, in the case of the children, the father in $48.7 \%$ and the mother in $51.3 \%$ of cases. Table 12 shows the differences in total scores 
and scores on the five subscales, according to which parent completed the questionnaire.

Table 12. Scores on Screen for Child Anxiety Related Disorders- Parent Version (SCARED-PV) for children with ASD according to which parent completed the scale

\begin{tabular}{|c|c|c|c|c|c|c|c|}
\hline Scales \& Sub-scales & & Parent & Mean & SD & df & $\mathbf{T}$ & p-value \\
\hline \multirow{2}{*}{$\begin{array}{l}\text { Total Anxiety } \\
\text { (SCARED-PV) }\end{array}$} & \multirow{2}{*}{ score } & Mothers & 59.71 & 13.758 & \multirow{2}{*}{581.588} & \multirow{2}{*}{2.692} & \multirow{2}{*}{$0.007 *$} \\
\hline & & Fathers & 62.26 & 9.758 & & & \\
\hline \multirow{2}{*}{\multicolumn{2}{|c|}{ Excessive Concern (PN) }} & Mothers & 18.68 & 4.971 & \multirow{2}{*}{573.674} & \multirow{2}{*}{2.576} & \multirow{2}{*}{$0.010^{*}$} \\
\hline & & Fathers & 19.55 & 3.428 & & & \\
\hline \multirow{2}{*}{\multicolumn{2}{|c|}{ Generalised Anxiety (GD) }} & Mothers & 13.27 & 3.186 & \multirow{2}{*}{604.123} & \multirow{2}{*}{3.008} & \multirow{2}{*}{$0.003^{*}$} \\
\hline & & Fathers & 13.95 & 2.473 & & & \\
\hline \multirow{2}{*}{\multicolumn{2}{|c|}{ Separation Anxiety (SP) }} & Mothers & 11.97 & 2.883 & \multirow{2}{*}{599.207} & \multirow{2}{*}{2.924} & \multirow{2}{*}{$0.004 *$} \\
\hline & & Fathers & 12.57 & 2.190 & & & \\
\hline \multirow{2}{*}{\multicolumn{2}{|c|}{ Social Phobia (SC) }} & Mothers & 10.16 & 2.377 & \multirow{2}{*}{612.993} & \multirow{2}{*}{1.222} & \multirow{2}{*}{0.222} \\
\hline & & Fathers & 10.37 & 1.928 & & & \\
\hline \multirow{2}{*}{\multicolumn{2}{|c|}{ School Anxiety (SH) }} & Mothers & 5.63 & 1.708 & \multirow{2}{*}{595.104} & \multirow{2}{*}{1.580} & \multirow{2}{*}{0.115} \\
\hline & & Fathers & 5.82 & 1.275 & & & \\
\hline
\end{tabular}

$\mathrm{SD}=$ standard deviation $*=\mathrm{p}<0.05$ (Student's t test).

The fathers rated the anxiety level of their children significantly higher than the mothers on the total score and on the three subscales Excessive Concern (PN), Generalized Anxiety (GD) and Separation Anxiety (SP), but on the subscales Social Phobia (SC) and School Anxiety (SH) there was no difference in scores between fathers and mothers. Younger parents tended to allocate higher anxiety scores $(\mathrm{p}<0.01)$.

No significant differences were found according to the marital status of the parents of the children with ASD in anxiety scores on SCARED-PV.

Table 13 shows the distribution of anxiety scores of children with ASD according to the parental educational level. Higher scores were recorded for the children of parents who had completed primary school than of those who had higher levels of education in the general score and on the subscales of SCARED-PV, with the exception of Social Phobia (SC).

Table 13. Scores on Screen for Child Anxiety Related Disorders - Parent Version (SCARED-PV) for children with ASD according to parental educational level

\begin{tabular}{lllll}
\hline Scales & Educational Level & Mean & SD & p-value \\
\hline \multirow{2}{*}{$\begin{array}{l}\text { Total Anxiety Disorder } \\
\text { SCARED-PV }\end{array}$} & Primary Education & 64.18 & 8.211 & $0.000^{*}$ \\
& Secondary Education & 59.98 & 12.410 & 13.205 \\
\hline \multirow{2}{*}{ Excessive Concern (PN) } & Higher/University Education & 60.04 & 2.784 & $0.000^{*}$ \\
& Primary Education & 18.82 & 4.495 & 4.726 \\
\hline & Secondary Education & 18.71 & 14.29 & 2.299 \\
Generalised Anxiety (GD) & Higher/University Education & 13.38 & 3.055 & $0.002^{*}$ \\
\hline
\end{tabular}




\begin{tabular}{lllll}
\hline & Primary Education & 12.88 & 1.885 \\
Separation Anxiety (SP) & Secondary Education & 12.10 & 2.617 & $0.004^{*}$ \\
& Higher/University Education & 12.06 & 2.848 \\
\hline \multirow{2}{*}{ Social Phobia (SC) } & Primary Education & 10.66 & 1.841 \\
& Secondary Education & 10.14 & 2.186 & 0.110 \\
& Higher/University Education & 10.16 & 2.312 & \\
\hline \multirow{2}{*}{ School Anxiety (SH) } & Primary Education & 6.06 & 1.093 & $0.009 *$ \\
& Secondary Education & 5.55 & 1.539 & 1.668 \\
\hline
\end{tabular}

$\mathrm{SD}=$ standard deviation $^{*}=\mathrm{p}<.05$.

Table 14 shows the influence of the economic status of the parents on the anxiety scores of their children with ASD.

Table 14. Scores on Screen for Child Anxiety Related Disorders - Parent Version (SCARED-PV) for children for ASD according to parental economic situation

\begin{tabular}{|c|c|c|c|c|}
\hline Scale & Economic Situation & Mean & SD & p-value \\
\hline \multirow{3}{*}{$\begin{array}{l}\text { Total Anxiety Disorder } \\
\text { SCARED-PV }\end{array}$} & Comfortable & 61.57 & 8.093 & \multirow{3}{*}{$0.007 *$} \\
\hline & Average & 60.39 & 14.431 & \\
\hline & Poor - Difficult & 60.27 & 16.025 & \\
\hline \multirow{3}{*}{ Excessive Concern (PN) } & Comfortable & 19.34 & 2.855 & \multirow{3}{*}{$0.004 *$} \\
\hline & Average & 18.84 & 5.224 & \\
\hline & Poor - Difficult & 18.98 & 5.667 & \\
\hline \multirow{3}{*}{ Generalised Anxiety (GD) } & Comfortable & 13.70 & 2.106 & \multirow{3}{*}{0.117} \\
\hline & Average & 13.53 & 3.357 & \\
\hline & Poor - Difficult & 13.43 & 3.747 & \\
\hline \multirow{3}{*}{ Separation Anxiety (SP) } & Comfortable & 12.39 & 1.947 & \multirow{3}{*}{0.318} \\
\hline & Average & 12.19 & 3.058 & \\
\hline & Poor - Difficult & 12.01 & 3.128 & \\
\hline \multirow{3}{*}{ Social Phobia (SC) } & Comfortable & 10.34 & 1,705 & \multirow{3}{*}{0.647} \\
\hline & Average & 10.20 & 2.429 & \\
\hline & Poor - Difficult & 10.17 & 2.825 & \\
\hline \multirow{3}{*}{ School Anxiety (SH) } & Comfortable & 5.79 & 1.199 & \multirow{3}{*}{0.635} \\
\hline & Average & 5.64 & 1.738 & \\
\hline & Poor - Difficult & 5.69 & 1.844 & \\
\hline
\end{tabular}

$\mathrm{SD}=$ standard deviation $^{*}=\mathrm{p}<0.05$ (Kruskal Wallis test).

The parents who reported a higher economic status rated the anxiety of their children with ASD significantly higher on the total SCARED-PV scale and the Excessive Concern (PN) subscale, but there was no significant difference in the scores on the other subscales. 


\section{Discussion}

The main purpose of this study was to assess the levels of anxiety disorder presented by school age children with ASD, in comparison with children of TD, according to their parents, focusing on the dimension of social and school stress. In addition, the relationship of factors in the family situation with the level of anxiety of the children with ASD was explored. Based on the findings, specific suggestions for parents of children with ASD are proposed on the management of anxiety, and in particular the anxiety of the child under consideration based solely on the parent's views. The psychometric properties of this instrument have been well established in children of TD by Birmaher's original validation studies (Birmaher, 1997; 1999), and later research (e.g. Hale et al., 2011). Silverman and Olendick (2005) reviewed the evidence for brief anxiety assessment tools in the general pediatric population and determined that the SCARED is among those with the most empirical support for discriminating between anxiety and other disorders in typically developing youth. Stern and colleagues used SCARED-PV to investigate anxiety symptoms in sample of children with ASD (Stern et al., 2015) and found high internal consistency (a $>0.9)$ for both ASD and TD. The responses can be calculated to provide specific subscales of anxiety, namely Excessive Concern (PN), Generalized Anxiety (GD), separation Anxiety (SP), Social Phobia (SC) and School Anxiety (SH). The study results showed that the parents of children with ASD rated that anxiety levels of their children high. According to the total score on SCARED-PV, $95.6 \%$ of the children with ASD were classified in the clinical spectrum of the scale, compared with $20 \%$ of the children of TD. In the five subscales, over $95 \%$ of the children with ASD were classified in the clinical spectrum, with the exception of Social Phobia (SC), for which the rate was $92 \%$.

The assessment by their parents of anxiety disorder as a whole for children with ASD has been reported in other studies (Gillot et al., 2001; Klin et al., 2000; Bitsika \& Sharpley, 2017). There is consistency in the views of parents of children with ASD in relation to the presence and magnitude of anxiety disorder in their children (Muris et al., 1998; Russel \& Sofronoff, 2005; Bellini, 2004; Kuriakose \& Lahiri, 2016). The same conclusions have been drawn from the focus on school stress among school children (Griffiths et al., 2017).

Of the factors associated with differences in the scores for the children with ASD, the fathers who had made the assessment rated the anxiety level of their children significantly higher than the mothers on the total score and on the subscales with the exception of Social Phobia (SC) and School Anxiety (SH) for which they allocated similar scores to the mothers.

The marital status of the parents was not related to differences in scores. Younger parents tended to allocate higher anxiety scores $(\mathrm{p}<0.01)$. Young parents without previous experience often cannot interpret a child's behavior correctly, they might not seek for services of assessment early and they might apply wrong motivations and make mistaken approaches.

Regarding the parental educational level, the parents who had completed primary school reported higher anxiety scores for their children with ASD than parents with higher levels of education, both in the general score and on the subscales of SCARED-PV, with the exception of Social Phobia (SC). The parents' educational level may influence their perceptions and attitudes towards ASD and anxiety, and affect their ability to identify characteristics of anxiety in their children with ASD.

The parents who characterized their economic status as a comfortable financial situation status rated the anxiety of their children with ASD significantly higher on the total SCARED-PV scale and the Excessive Concern (PN) subscale. The financial situation of a family in an important factor in the management of anxiety as it influences the time that parents will seek for assessment, whether or not they seek for early intervention (O'Nions et al., 2017).

\subsection{Recommendations for Parental Support}

Based on the study findings and on the relevant bibliography, several measures could be proposed for the parents of children with ASD to facilitate their inclusion into the mainstream or special school (Bitsika \& Sharpley, 2017), Parents and caregivers can "manage" the environment; they can provide a structured physical environment at home that would facilitate their children's self-motivation, understanding and relaxation, and a structured daily schedule. They can prepare the child for any possible changes (O'Nionset et al., 2017). Parents can reduce sensory stimuli that might provoke confusion or overload in children with ASD at home (Corbett et al., 2016), but reducing all sensory stimuli is not something can easily be managed outside of the home environment. It would thus be helpful, also to help children to cope in challenging situations. Parents can participate in the assessment of stimuli and their children's reactions. They can learn to distinguish trait anxiety from state anxiety, and possible difference in psychological stress (Edmond et al., 2017). They can learn how the child reacts, which stimuli provoke 
repetitive anxiety symptoms and which cause occasional reactions (Ventola et al., 2017). Their systematic observation of their children's situation, and the time and place when anxiety symptoms appear (e.g. when the child is tired, is hungry, cannot accomplish a task, understand stimuli, is shy with adults, is disturbed by other children, either known or unknown etc.) can help them to anticipate these situations. They can observe stimuli that trigger their children's anxiety symptoms, and avoid those particular stimuli. Control of stimuli, but also exposure of the child to them and encouraging development of the skills to cope with them, cultivation of social skills and, in general, participation of other members of the family can all help. Alternative systems of communication can facilitate expression of desires and needs as well as the expansion accumulated tension. Parents need to be well informed on the management of their children's potential manifestation of anxiety at school and cooperate with the teachers and the other staff of the school on the management of anxiety symptoms. Implementation of techniques and approaches that increase social skills and comprehension of the social environment (e.g., the circle of friends) (Yen et al., 2002) can ameliorate the behavioral responses of adolescents with ASD to perceived social threat.

\section{Conclusions}

This study showed that, as assessed by their parents, the anxiety level of school children with ASD is extremely high. Anxiety can impair the adaptation and inclusion of these children in their social environment, and in particular the school setting. Parents who are aware of their children's anxiety can help them to manage it. The practical value of the research lies in its contribution to assessing the people's with ASD anxiety symptoms and the investigation of the role of the parents.

The study revealed the perceptions of parents of the type, and levels of anxiety in their children with ASD. It showed that the family situation, including the educational and economic level of the parents influence their perception of anxiety symptoms in their children's with ASD. Parents spend many hours with their children and can influence the formation of an environment that increases their children's understanding of what is happening around them. Parental interventions can influence the adaptation and inclusion in the school social environment. Efforts could be made to inform parents with children with ASD on how to deal with their children's anxiety disorder through seminars, informative talks and printed materials.

\subsection{Research Limitations}

The geographic distribution of the sample can be considered as a basis limitation. Despite is the large sample size the distribution was not uniform throughout Greece, for either the ASD or the TD group. It is possible that there was some bias in the self selection of the parents of children of TD, as the rate of clinical spectrum anxiety was quite high in that group, and may not be representative of the population. Consequently, generalizations of the conclusions drawn should be made subject to caution.

No other possible causes of anxiety disorder were evaluated, such as depression, loneliness and interpersonal relationships of either the children with ASD or those of TD.

All the above limitations must be taken into account when considering and interpreting the findings of this research.

\subsection{Suggestions for Further Research}

All of the above restrictions could be the basis for further research to study in more detail the parental perceptions of anxiety in their children with ASD.

Future studies should ensure systematic sampling of parents of both children with ASD and those with TD, with special care to avoid self-selection sampling bias in the latter. In addition it would be of interest to elicit the views on the same child of both parents, and of parent and teacher, in order to explore more thoroughly the components of the anxiety in the children with ASD.

\section{References}

American Psychiatric Association. (2013). Diagnostic and statistical manual of mental disorders (5th ed.). Arlington, VA: American Psychiatric Publishing. https://doi.org/10.1176/appi.books.9780890425596

Arab, A., El Kesky, M., \& Hadwin, J. A. (2016). Psychometric Properties of the Screen for Child Anxiety Related Emotional Disorders (SCARED) in a Non-Clinical Sample of Children and Adolescents in Saudi Arabia. Child Psychiatry Hum Dev., 47, 554-562. https://doi.org/10.1007/s10578-015-0589-0

Attwood, T. (2005). Asperger's Syndrome Guide for Parents and Professionals. UK: Kingsley Plc Ltd.

Bellini, S. (2004). Social Skill Deficits and Anxiety in High-Functioning Adolescents With Autism Spectrum Disorders. Focus on Autism and Other Developmental Disorders, 19(2), 78-86. 
https://doi.org/10.1177/10883576040190020201.

Birmaher, B., Brent, D. A., Chiappetta, L., Bridge, J., Monga, S., \& Baugher, M. (1999). Psychometric properties of the screen for child anxiety related emotional disorders (SCARED): A replication study. Journal of the American Academy of Child and Adolescent Psychiatry, 38(10), 1230-1236. https://doi.org/10.1097/00004583-199910000-00011.

Bitsika, V., \& Sharpley, C. F. (2017). The association between parents' ratings of ASD symptoms and anxiety in a sample of high-functioning boys and adolescents with Autism Spectrum Disorder. Res Dev Disabil, 63, 38-45. https://doi.org/10.1016/j.ridd.2017.02.010

Bradley, E. A., Summers, J. A., Wood, H. L., \& Bryson, S. E. (2004). Comparing rates of psychiatric and behavior disorders in adolescents and young adults with severe intellectual disability with and without autism. Journal of Autism and Developmental Bisorders, https://doi.org/10.1023/B:JADD.0000022606.97580.19

Corbett, B. A., Muscatello, R. A., \& Blain, S. D. (2016). Impact of sensory sensitivity on physiological stress response and novel peer interaction in children with and without autism spectrum disorder. Frontiers in Neuroscience, 10, 278. https://doi.org/10.3389/fnins.2016.00278

Costello, E. J., Egger, H. L., \& Angold, A. (2005). The developmental epidemiology of anxiety disorders: phenomenology, prevalence, and comorbidity. Child Adolesc Psychiatr Clin N Am., 14(4), 631-48, vii. https://doi.org/10.1016/j.chc.2005.06.003

Dekker, M. C., \& Koot, H. M. (2003). DSM-IV disorders in children with borderline to moderate intellectual disability and impact. Journal of the American Academy of Child and Adolescent Psychiatry, 42(8), 915. https://doi.org/10.1097/01.CHI.0000046892.27264.1A

Edmiston, E.K., Blain, S. D., \& Corbett, B. A. (2017). Salivary cortisol and behavioral response to social evaluative threat in adolescents with autism spectrum disorder. Autism Research, 10(2), 346-358. https://doi.org/10.1002/aur.1660

Evans, D. W., Canavera, K., Kleinpeter, F. L., Maccubbin, E., \& Taga, K. (2005). The fears, phobias and anxieties of children with autism spectrum disorders and Down syndrome: Comparisons with developmentally and chronologically age matched children. Child Psychology and Human Development, 36, 3-26. https://doi.org/10.1007/s10578-004-3619-x

Drahota, A., Wood, J. J., Sze, K. M., \& Van Dyke, M. (2011). Effects of Cognitive Behavioral Therapy on Daily Living Skills in Children with High- Functioning Autism and Concurrent Anxiety Disorders. J Autism Dev Disord, 41(3), 257-265. Published online 2010 May 28. https://doi.org/10.1007/s10803-010-1037-4

Ghaziuddin, M. (2005). A family history study of Asperger syndrome. J Autism Dev Disord., 35(2), 177-82.

Gillott, A., Furniss, F., \& Walter, A. (2001). Anxiety in high functioning children with autism. Autism: The International Journal of Research and Practice, 5(3), 277-286. https://doi.org/10.1177/10883576060210010401

Greek Official Government Gazette. (2008). Law 3699/2.10.2008/199. Special Education and Education of the Handicapped or Those With Special Educational Needs (in Greek).

Griffiths, D. L., Farrell, L. J., Waters, A. M., \& White, S. W. (2017). ASD Traits Among Youth with Obsessive-Compulsive Disorder. Child Psychiatry Hum Dev. https://doi.org/10.1007/s10578-017-0714-3

Højgaard, D. R. M. A., Skarphedinsson, G., Nissen, J. B., Hybel, K. A., Ivarsson, T., \& Thomsen, P. H. (2017). Pediatric obsessive-compulsive disorder with tic symptoms: clinical presentation and treatment outcome. Eur Child Adolesc Psychiatry, 26(6), 681-689. https://doi.org/10.1007/s00787-016-0936-0

Kim, J. A., Szatmari, P., Bryson, S. E., Streiner, D. L., \& Wilson, F. J. (2000). The prevalence of anxiety and mood problems among children with autism and Asperger syndrome. Autism, 4(2), 117-132. https://doi.org/10.1177/1362361300004002002

Klin, A., Schultz, R., \& Cohen, D. (2000). Theory of mind in action: developmental perspectives on social neuroscience. In: Baron-Cohen S, Tager-Flusberg H, Cohen D, editors. Understanding Other Minds: Perspectives from Developmental Neuroscience (pp. 357-388). Oxford: Oxford University Press.

Kuriakose, S., \& Lahiri, U. (2016). Design of a Physiology-sensitive VR-based Social Communication Platform for Children with Autism. IEEE Trans Neural Syst Rehabil Eng. 
https://doi.org/10.1109/TNSRE.2016.2613879

MacNeil, B. M., Lopes, V. A., \& Minnes, P. M. (2009). Anxiety in children and adolescents with autism spectrum disorders. Research in Autism Spectrum Disorders, 3(1), 1-21. https://doi.org/10.1016/j.rasd.2008.06.001

Merikangas, K. R., He, J. P., Brody, D., Fisher, P. W., Bourdon, K., \& Koretz, D. S. (2010). Prevalence and treatment of mental disorders among US children in the 2001-2004 NHANES. Pediatrics, 125(1), 75-81. https://doi.org/10.1542/peds.2008-2598

Merikangas, K. R., He, J. P., Burstein, M., Swanson, S., Avenevoli, S., Cui, L., ... Swendsen, J. (2010). Lifetime Prevalence of Mental Disorders in US Adolescents: Results from the National Comorbidity Study-Adolescent Supplement (NCS-A). J Am Acad Child Adolesc Psychiatry, 49(10), 980-989. https://doi.org/10.1016/j.jaac.2010.05.017

Muris, P., Merckelbach, H., Wessel, I., \&Ven, M. (1999). Psychopathological correlates of self-reported behavioral inhibition in normal children. Behaviour Research and Therapy, 37, 575-584. https://doi.org/10.1016/S0005-7967(98)00155-7

O'Nions, E., Happé, F., Evers, K., Boonen, H., \& Noens, I. (2017). How do Parents Manage Irritability, Challenging Behaviour, Non-Compliance and Anxiety in Children with Autism Spectrum Disorders? A Meta-Synthesis. J Autism Dev Disord., 8. https://doi.org/10.1007/s10803-017-3361-4

Papadatos, J. (2010). Psychological Disorders and Learning Difficulties. Athens: Gutenberg Plc.

Pine, D. S., Cohen, P., Gurley, D., Brook, J., \& Ma, Y. (1998). The risk for early-adulthood anxiety and depressive disorders in adolescents with anxiety and depressive disorders. Archives of General Psychiatry, 55(1), 56.

Polychronopoulou, S. (2012). Children and Adolescents with special needs and possibilities. Athens.

Russell, E., \& Sofronoff, K. (2005). Anxiety and social worries in children with Asperger syndrome. Australian and New Zealand Journal of Psychiatry, 39(7), 633-638. https://doi.org//10.1080/j.1440-1614.2005.01637.x

Simonoff, E., Pickles, A., Charman, T., Chandler, S., Loucas, T., \& Baird, G. (2008). Psychiatric disorders in children with autism spectrum disorders: Prevalence, comorbidity, and associated factors in a population-derived sample. Journal of the American Academy of Child and Adolescent Psychiatry, 47(8), 921. https://doi.org/10.1097/CHI.0b013e318179964f

Stern, J. A., Gadgil, M. S., Blakeley-Smith, A., Reaven, J. A., \& Hepburn, S. L. (2015). Psychometric Properties of the SCARED in Youth with Autism Spectrum Disorder. Res Autism Spectr Disord., 1, 8(9), 1225-1234. https://doi.org/10.1016/j.rasd.2014.06.008

van Steensel, F. J. A., Bogels, S. M., \& Perrin, S. (2011). Anxiety disorders in children and adolescents with autistic spectrum disorders: A meta-analysis. Clinical Child and Family Psychology Review, 14(3), 302-317. https://doi.org/10.1007/s10567-011-0097-0.

Ventola, P., Lei, J., Paisley, C., Lebowitz, E., \& Silverman, W. (2017). Parenting a Child with ASD: Comparison of Parenting Style Between ASD, Anxiety, and Typical Development. J Autism Dev Disord., 47(9), 2873-2884. https://doi.org/10.1007/s10803-017-3210-5

White, S. W., \& Roberson-Nay, R. (2009). Anxiety, social deficits, and loneliness in youth with autism spectrum disorders. Journal of Autism and Developmental Disorders, 39, 1006-1013. https://doi.org/10.1007/s10803-009-0713-8

White, S. W., Oswald, D., Ollendick, T., \& Scahill, L. (2009). Anxiety in children and adolescents with autism spectrum disorders. Clinical Psychology Review, 29(3), 216-229. https://doi.org/10.1016/j.cpr.2009.01.003.

Yen, L. L, Chen, L, Lee, S. H., Hsiao, C., \& Pan, L. Y. (2002). Child and adolescent behaviour in long-term evolution (CABLE): a school-based health lifestyle study. Promot Educ., Suppl. 1, 33-40. https://doi.org/10.1177/10253823020090010115

Yen, M. H., Chiu, C. H., Huang, Y. C., \& Lin, T. Y. (2011). Effects of lactoferrin-containing formula in the prevention of enterovirus and rotavirus infection and impact on serum cytokine levels: a randomized trial. Chang Gung Med J., 34(4), 395-402. 


\section{Appendix}

\section{Letter to Parents}

Dear parents, we kindly ask you to fill in the questionnaire below in order to gather data on the anxiety problems that many children are experiencing today in and out of school.

We live in an age that creates stress and stress on all of us. Stress refers to any situation that affects our organization and requires adaptation reactions. Problems start when the stress reaction is triggered regularly, so our body is in a state of readiness and is tortured, often for insignificant reasons. Many believe that children are not experiencing such situations. But our experience proves the opposite.

Dear parents, we hope that the findings of our study will inform and sensitize teachers, as well as the Greek State, on issues concerning the anxiety of children with or without special needs. So we will design intervention programs that will help the child to cope properly with the anxious situations that prevent his / her school and extra-curricular adaptation and disrupt his / her own family and family.

Thank you again for your participation

C... S.

Assistant Professor at the Department of

of the University of

\section{DETECTION OF SITUATIONS WITH ANXIETY}

Please note by putting $\mathrm{X}$ or circle the word that fits your answer or answer in a few words.

Gender of the Parent: Man Woman

1. Family status: Married _ Divorced _ Single

New companion/ spouse

2. Age: years.

3. Education: Master's Degree __, University Degree __, Higher Technical Education Degree/ Higher School

High school certificate , Primary school certificate , Did not finish Primary school

4. Occupation:

6. Financial condition: Your financial situation is considered to be Comfortable/wealthy Average Poor Difficult

Put $\mathrm{X}$ in one of the 3 columns you will choose according to your answer $(0,1, \quad 2)$.

\section{Child's characteristics}

1. Gender: Boy

Girl

2. Age

3. Class he/she attends

4. I.Q.

5. No speech Monosyllabic speech Developed speech 
Screen for Child Anxiety Related Disorders- Parent Version

\begin{tabular}{|c|c|c|c|}
\hline My child & $\begin{array}{l}0 \\
\text { It is not true } \\
\text { or is rarely } \\
\text { true }\end{array}$ & $\begin{array}{l}1 \\
\text { It is true } \\
\text { sometimes or only } \\
\text { a few times }\end{array}$ & $\begin{array}{l}2 \\
\text { It is always } \\
\text { true or true } \\
\text { very often }\end{array}$ \\
\hline $\begin{array}{l}\text { 1. When my child feels horrified, he/she has difficulty } \\
\text { breathing. }\end{array}$ & & & \\
\hline 2. He/She has headaches when he/she is in school. & & & \\
\hline 3. Does not like being with people who does know well. & & & \\
\hline 4. Feels afraid to sleep away from home & & & \\
\hline 5. Worries about being liked by others. & & & \\
\hline 6. When frightened feels like losing his/her senses. & & & \\
\hline 7. Is nervous. & & & \\
\hline 8. Follows me everywhere I go. & & & \\
\hline 9. Others tell me that my child looks nervous. & & & \\
\hline $\begin{array}{l}\text { 10. My child feels nervous with people he/she does not } \\
\text { know well. }\end{array}$ & & & \\
\hline 11. He/She has a stomach ache at school. & & & \\
\hline 12. When scared, he/she feels like crazy. & & & \\
\hline 13. Is worried about sleeping on his/her own. & & & \\
\hline $\begin{array}{l}\text { 14. My child is worried about being as good as other } \\
\text { children. }\end{array}$ & & & \\
\hline $\begin{array}{l}\text { 15. When he/she feels scared, he/she feels like } \\
\text { experiencing non-real situations. }\end{array}$ & & & \\
\hline $\begin{array}{l}\text { 16. He/She has nightmares about whether something } \\
\text { bad will happen to his/her parents. }\end{array}$ & & & \\
\hline 17. He/She worries when he/she thinks going to school. & & & \\
\hline $\begin{array}{l}\text { 18. When frightened, his/her heart beats very fast } \\
\text { (fast-paced). }\end{array}$ & & & \\
\hline 19. My child has begun to become fearful (dangerous). & & & \\
\hline $\begin{array}{l}\text { 20. He/She often has nightmares about whether } \\
\text { something bad will happen to him/her. }\end{array}$ & & & \\
\hline 21. He/She is worried about whether things will go well. & & & \\
\hline 22. When scared, sweats too much. & & & \\
\hline 23. Worries about everything. & & & \\
\hline 24. Gets scared for real for no reason. & & & \\
\hline 25. Is afraid to stay alone at home. & & & \\
\hline $\begin{array}{l}\text { 26. Finds difficult to speak to someone who does not } \\
\text { know well. }\end{array}$ & & & \\
\hline 27. When scared feels choking. & & & \\
\hline 28.Others tell me that my child worries too much. & & & \\
\hline $\begin{array}{l}\text { 29. My child does not like being away from his/her } \\
\text { family. }\end{array}$ & & & \\
\hline 30. He/Her is afraid of anxiety crisis (panic). & & & \\
\hline
\end{tabular}




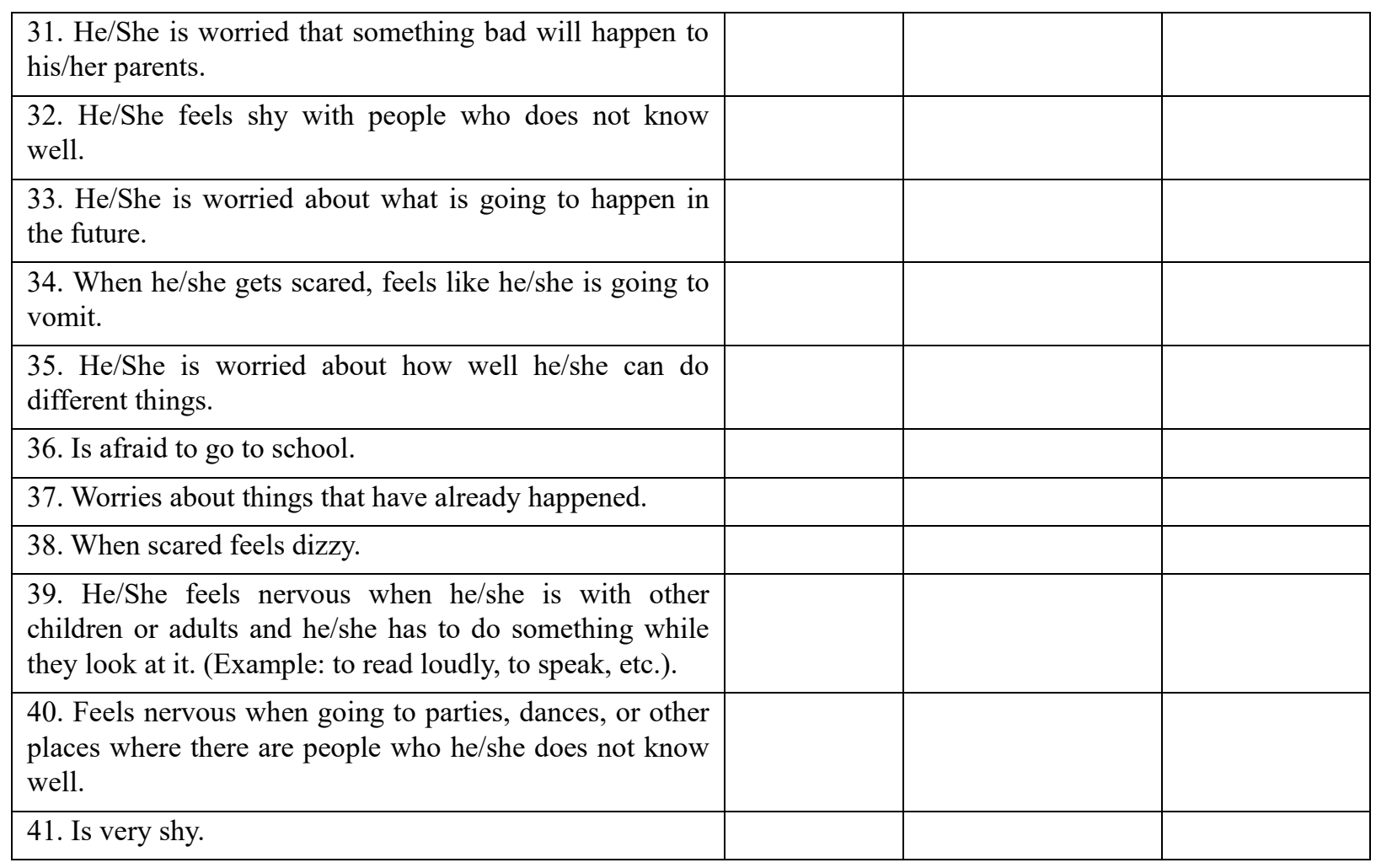

\section{Copyrights}

Copyright for this article is retained by the author(s), with first publication rights granted to the journal.

This is an open-access article distributed under the terms and conditions of the Creative Commons Attribution license (http://creativecommons.org/licenses/by/4.0/). 